\title{
Salinity effects on immune parameters of Ruditapes philippinarum challenged with Vibrio tapetis
}

\author{
H. I. Reid ${ }^{1}$, P. Soudant ${ }^{2}$, C. Lambert ${ }^{2}$, C. Paillard ${ }^{2}$, T. H. Birkbeck ${ }^{1, *}$ \\ ${ }^{1}$ Division of Infection and Immunity, Institute of Biomedical and Life Sciences, Joseph Black Building, University of Glasgow, \\ Glasgow G12 8QQ, UK \\ ${ }^{2}$ Université de Bretagne Occidentale, Institut Universitaire Européen de la Mer, 29280 Plouzane, France
}

\begin{abstract}
The occurrence of brown ring disease (BRD) in farmed Manila clams Ruditapes philippinarum is seasonal. Development of the disease is believed to require the presence of the infective agent Vibrio tapetis and particular environmental conditions. This paper studies the effect of salinity (20 to $40 \%$ ) on measurable immune parameters of Manila clams, and the progression of BRD in experimentally infected individuals. At $20 \%$ salinity, the total haemocyte count was reduced and disease prevalence was highest. At $40 \%$ salinity significantly fewer clams presented signs of BRD, and this was correlated with increases in the total haemocyte count, hyalinocyte count, phenoloxidase levels and phagocytic activity of haemocytes. Inoculation of clams with $V$. tapetis did not have a significant effect on the immune parameters measured. Thus, this laboratory-based study relates environmental stress to disease development.
\end{abstract}

KEY WORDS: Vibrio tapetis $\cdot$ Brown ring disease $\cdot$ Aquaculture $\cdot$ Salinity $\cdot$ Immune response Resale or republication not permitted without written consent of the publisher

\section{INTRODUCTION}

The Manila clam Ruditapes philippinarum is one of the most extensively cultivated bivalve molluscs, with a worldwide production of approximately 1.7 million $t$ $\mathrm{yr}^{-1}$ (FAO 1999). After the introduction of Manila clams into Europe 30 yr ago (LeBorgne 1996), a new disease syndrome appeared which caused high mortalities and was recognised by brown deposits of conchiolin on the inner face of the shell (Paillard et al. 1989). The syndrome, termed brown ring disease (BRD), first occurred in Manila clams cultured in France and was shown to be caused by a new bacterial species, Vibrio P1, later named Vibrio tapetis (Paillard et al. 1994, Borrego et al. 1996).

BRD has subsequently been detected in clams in Spain, Italy and the south coast of England (Paillard et al. 1994, Allam et al. 2000b), but not in other regions of the world where it is cultivated, e.g. SE Asia, Japan, Canada or the USA. The natural habitat and distribution of Vibrio tapetis is not known. Until recently, this organism had been detected only in diseased clams and surrounding sediments (Paillard et al. 1994), but it may be much more widespread, as avirulent strains have now been isolated from Norway (C. Paillard pers. comm.) and cultivated Atlantic halibut in Scotland (Reid et al. 2003). As disease prevalence is seasonal and depends on the location of the clams, environmental conditions are thought to affect clam susceptibility to BRD. It has previously been shown that temperature modulates BRD expression and immune responses in Ruditapes philippinarum (Allam et al. 2002). Salinity effects on the prevalence of other diseases in bivalves have also been demonstrated (Ford \& Haskin 1988, Chu et al. 1993).

We report on experimental studies performed to evaluate the effect of different salinities on Manila clam susceptibility to BRD, and the effect of salinity on measurable parameters of the clam immune response.

\section{MATERIALS AND METHODS}

Bacterial strains and culture. Bacteria were routinely cultured on tryptic soy agar (TSA) or tryptic soy broth (TSB) supplemented with $1.5 \%(\mathrm{w} / \mathrm{v})$ sodium chloride. 
To ascertain salinity tolerance, Strains CECT $4600^{\mathrm{T}}$ and IS1 of Vibrio tapetis were cultured at a range of salinities from 5 to $60 \%$ in TSB; salinity was adjusted by addition of appropriate amounts of a stock solution of $20 \%(\mathrm{w} / \mathrm{v}) \mathrm{NaCl}$ in TSB. The medium was dispensed in $200 \mu \mathrm{l}$ vol in a 96-well microtitre plate, and at each salinity triplicate wells were inoculated with $10 \mu \mathrm{l}$ of a standard suspension of $V$. tapetis to a final concentration of $10^{6}$ bacteria $\mathrm{ml}^{-1}$. The plates were incubated at $20^{\circ} \mathrm{C}$ with gentle shaking, and growth was measured as the mean optical density at $600 \mathrm{~nm}$.

For the inoculation of clams, bacteria were cultured in $100 \mathrm{ml}$ TSB at salinities of 20,30 and $40 \%$, at $20^{\circ} \mathrm{C}$ with gentle shaking in an orbital incubator.

Inoculation of clams. Adult Manila clams (35 to $40 \mathrm{~mm}$ ) were obtained from Marennes, France. The clams were maintained in twelve $50 \mathrm{l}$ aquaria with under-gravel filters containing aerated artificial seawater (ASW) at 20, 30 and $40 \%$. Clams were held at a density of 1 individual $\mathrm{l}^{-1}$ water and at a temperature of $15.5 \pm 1.5^{\circ} \mathrm{C}$. Upon arrival at the laboratory, the clams were initially held in ASW at $30 \%$ salinity for $2 \mathrm{~d}$, after which time the salinity was adjusted as necessary over a 6 d period ( $3.3 \%$ every 2 d) from $30 \%$ to 20 or $40 \%$ (4 aquaria per salinity, each containing 50 clams). Clams were held for a further week before inoculation to allow acclimatisation.

A third of the volume of water was exchanged with fresh ASW of the appropriate salinity 3 times a week. Water was removed from the tanks with a siphon, and faecal waste was removed from the bottom of the tanks during this procedure. It was established by measuring levels of nitrite and ammonia (TetraTests, TetraWerke) that this cleaning/water-replacement regime maintained low concentrations of these toxic compounds.

For the duration of the experiment, clams were fed daily on a mixed algal diet of $1 \times 10^{7}$ Pavlova lutheri and $1 \times 10^{6}$ Tetraselmis suecica cells clam ${ }^{-1} \mathrm{~d}^{-1}$.

The clams were inoculated as described by Paillard \& Maes (1994). Vibrio tapetis was grown overnight in TSB at the ambient salinity of each clam group, and $0.5 \mathrm{ml}$ suspensions of bacteria, standardised to $10^{8}$ cells $\mathrm{ml}^{-1}$ in ASW of the appropriate salinity, were injected into the pallial cavity of the clams (50 clams per salinity treatment, 2 replicates for each treatment). Control clams were inoculated with $0.5 \mathrm{ml}$ sterile ASW.

Characterisation and classification of BRD syndrome. Disease progression was monitored in accordance with descriptions by Paillard \& Maes (1994). Conchiolin-deposit stages and shell-repair stages were established using the classification system outlined by the same authors.

Fluid sampling. Haemolymph and extrapallial fluid were sampled from each clam; 20 clams from each salinity group were sampled after the clams had acclimatised to their different environments for $7 \mathrm{~d}$ but had not been inoculated (T0). At 4 wk post-inoculation (T28), a further 20 clams were sampled from each group. Haemolymph $\left(0.7\right.$ to $1.0 \mathrm{ml}$ ind. ${ }^{-1}$ ) was withdrawn from the posterior adductor muscle by inserting a syringe needle through the soft tissue at the base of the umbo. Extrapallial fluid was collected by slipping a needle between the shell and the mantle after the valves had been opened and allowing the pallial fluid to drain away.

Immune parameters. Total haemocyte counts and haemocyte viability: Immediately after extraction, haemolymph samples were mixed with an equal volume of ice-cold $0.2 \%$ trypan blue in ASW, and kept on ice for several minutes before examination. Total and viable cells were counted together on a haemocytometer. Results are presented as total haemocyte count $\mathrm{ml}^{-1}$, and as percentage dead cells.

Differential haemocyte counts: To perform differential haemocyte counts, an equal volume of $6 \%$ formalin in seawater was added to haemolymph $(200 \mu \mathrm{l})$ and the cell suspension stored at $4^{\circ} \mathrm{C}$. A FACSCalibur (Becton Dickinson) flow-cytometer was used to determine the prevalence of haemocyte cell populations (granulocytes and hyalinocytes) by counting events in the cell population defined according to their position in a forward-scatter to side-scatter (FSC/SSC) density-plot. For each cell population, the 'size' (FSC mean value) and 'complexity' (SSC mean value) of the cell population was determined.

Haemolymph enzymes: Haemolymph samples were separated into cellular and supernatant fractions by centrifugation prior to freezing. Phenoloxidase and leucine amino peptidase levels were measured in both cellular and supernatant fractions of the haemolymph.

DOPA-oxidase activity: We placed $60 \mu \mathrm{l}$ vol of haemolymph in each well of a 96 -well microtitre plate; $50 \mu \mathrm{l}$ of Tris- $\mathrm{HCl}$ buffer $(0.2 \mathrm{M}, \mathrm{pH}=8)$ and $100 \mu \mathrm{l}$ of $20 \mathrm{mM}$ L-dopamine (L-DOPA) (Sigma) were then added. The microtitre plate was rapidly mixed for $10 \mathrm{~s}$, after which time the phenoloxidase reaction was measured at ambient temperature on a Multiskan MS microplate-reader (Life Sciences International), using a $490 \mathrm{~nm}$ wavelength filter and a kinetic programme (Genesis, Windows Software for microtitre plate-based assays), with the optical density recorded every $5 \mathrm{~min}$ over a period of $1 \mathrm{~h}$. The microtitre plate was mixed prior to each measurement. Controls, without cells but containing L-DOPA, were run in parallel and the values subtracted from the test values to correct for autooxidation of the L-DOPA. All samples were measured in duplicate and results are expressed as changes in optical density $\mathrm{mg}^{-1}$ protein. 
Lysozyme: Lysozyme concentration was measured in triplicate for each sample, using hen egg-white lysozyme standards (40 to $0.6 \mu \mathrm{g} \mathrm{ml}^{-1}$ ) in 96-well microtitre plates. The whole haemolymph samples had been stored frozen at $-70^{\circ} \mathrm{C}$ for approx. $2 \mathrm{wk}$. Lysozyme standards or samples $(20 \mu \mathrm{l})$ were transferred into wells, and $180 \mu \mathrm{l}$ of Micrococcus lysodeikticus suspension at $\mathrm{OD}_{600}=0.4$ in $0.06 \mathrm{M}$ sodium phosphate buffer ( $\mathrm{pH}$ 6.4) were added to each well. As low concentrations of lysozyme were found in these samples, the plates were incubated for $1 \mathrm{~h}$ at room temperature before reading the absorbance at $540 \mathrm{~nm}$.

Protein concentration: Total protein concentration was measured in the haemolymph samples using the method of Bradford (1976) with bovine serum albumin as standard.

Leucine amino peptidase activity: Haemolymph from each clam $(100 \mu \mathrm{l})$ was placed in a well of a 96well microtitre plate. To each well, $75 \mu$ l of Tris- $\mathrm{HCl}$ (0.2 M, pH 8.0) was added, followed by $25 \mu$ of the substrate leucine p-nitroanilide $(10 \mathrm{mM}$ in deionized

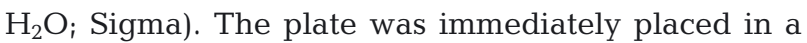
microtitre plate reader and the rate of colour change monitored at $405 \mathrm{~nm}$ for $20 \mathrm{~min}$. All samples were measured in duplicate, and the results are expressed as changes in optical density (OD) $\mathrm{mg}^{-1}$ of protein.

Condition index: The condition index of the clams was calculated as dried flesh weight/dry shell weight (Lucas \& Beninger 1985).

Haemocyte immunocompetence assays. In vitro cytotoxicity assay: The response of clam haemocytes to Vibrio tapetis was tested on haemocytes in an in vitro assay, as described by Lane \& Birkbeck (2000). Briefly, haemolymph extracted from 10 clams from each group was pooled and tested in the assay. Haemocytes allowed to attach to the flat surface of a microtitre plate were exposed to $V$. tapetis suspended in $0.2 \mu \mathrm{m}$-filtered haemolymph at a concentration of 50 bacteria haemocyte $^{-1}$ for $3 \mathrm{~h}$. The percentage of cells which rounded up in response to the bacterial challenge was recorded and corrected for the percentage of haemocytes rounded in control cells not exposed to bacteria. For these experiments, V. tapetis was cultured at the 3 salinities at which clams had been maintained, and each haemolymph pool was tested separately with $V$. tapetis raised at each salinity.

In vitro phagocytosis assay: A phagocytosis assay was performed following the method described by Allam et al. (2002). Fluorescent beads of $2 \mu \mathrm{m}$ diameter in $100 \mu \mathrm{l}$ of haemolymph (50 beads haemocyte ${ }^{-1}$ ) were placed in a microtitre plate for $3 \mathrm{~h}$. The phagocytic activity was measured in vitro by means of a flow cytometer using the filter FL1 at $525 \mathrm{~nm}$ to detect fluorescent beads taken into the cells. Control reactions performed in parallel either had no beads added to the haemolymph, or a cytoskeleton inhibitor of phagocytosis was added. The phagocytic rate of each sample was determined according to Allam et al. (2002).

Statistical analyses. Differences between inoculated and control groups, and differences between clams maintained at different salinities within each group, were analysed by ANOVA (followed by Tukey's HSD test) where applicable, and otherwise by non-parametric methods (Kruskal-Wallis and Mann-Whitney $U$ test). Differences were considered to be statistically significant at $\mathrm{p}<0.05$. To observe the overall effect of salinity on the clams, data from challenged and control groups were pooled. Similarly, to see if there was a universal effect of inoculation, data from all salinity groups were pooled. As only 1 of the factors measured (lysozyme) yielded data that was normally distributed (Anderson-Darling and Ryan-Joiner tests), most data was analysed using non-parametric tests. Data was transformed where necessary to give a normal distribution for better correlation analyses.

\section{RESULTS}

\section{Effect of salinity on Vibrio tapetis growth}

At $20^{\circ} \mathrm{C}$, Vibrio tapetis grew most rapidly at salinities between 20 and $40 \%$, but was capable of growth over a range from $10 \%$ to at least $60 \%$. At 20 to $40 \%$, the maximum OD $600 \mathrm{~nm}$ was recorded after 14 to $16 \mathrm{~h}$, declining thereafter, but a longer time was required to reach maximum $O D$ at salinities outside this range (Fig. 1).

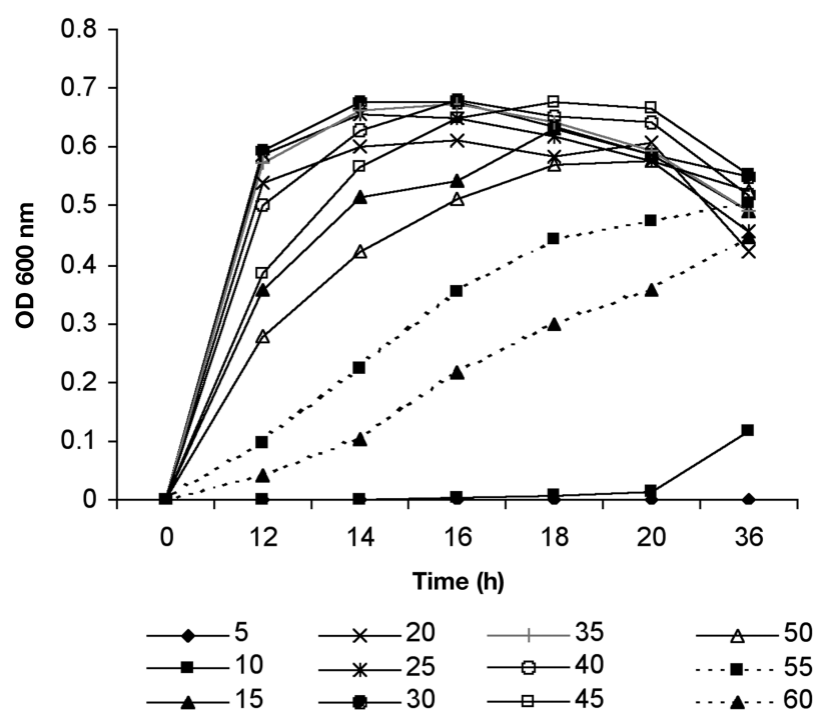

Fig. 1. Vibrio tapetis Strain IS1. Growth in tryptic soy broth at $20^{\circ} \mathrm{C}$ from 5 to $60 \%$ salinity, OD $600 \mathrm{~nm}$ measured at time (t) post-inoculation of broth 


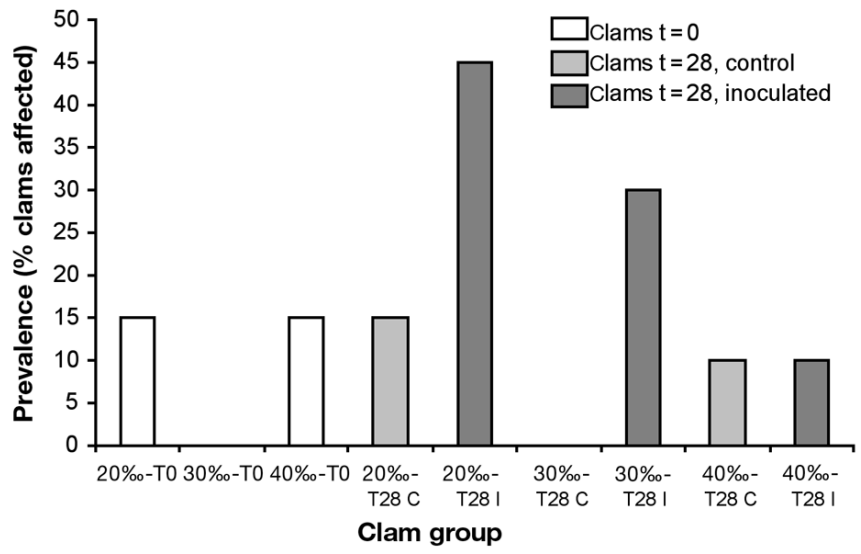

Fig. 2. Vibrio tapetis. Prevalence $(n=20)$ of brown ring disease in Manila clams inoculated with artificial seawater (controls, C) or with $V$. tapetis (inoculated, I). T0 clams were acclimatised to given salinity but not inoculated; T28 clams were maintained at given salinity for 4 wk post-inoculation

\section{BRD prevalence}

Among the 600 clams inoculated for the experiment, there were only 12 mortalities ( $2 \%)$, indicating that the water quality and maintenance regime were satisfactory for the duration of the experiment.

The prevalence of BRD is shown in Fig. 2. At the beginning of the experiment, early stages of disease were detected in clams acclimatised to 20 or $40 \%$ that had not been experimentally inoculated with Vibrio tapetis, and 4 wk later (T28), a similar level of BRD was still present in clams from these control groups. There was no difference in BRD prevalence between inoculated and control clams held at $40 \%$, but at salinities of 30 and $20 \%$, the disease in inoculated clams was significantly greater than the background level in control clams. The effect of inoculation with $V$. tapetis was

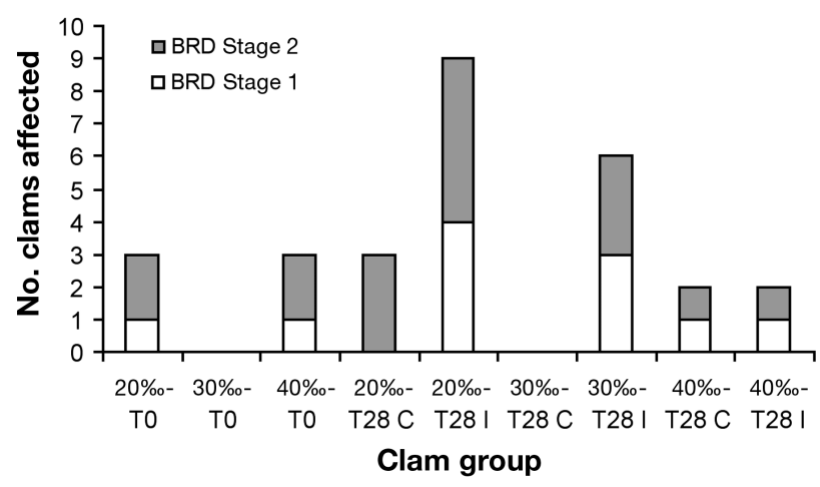

Fig. 3. Vibrio tapetis. Stages of disease development in BRD affected clams. $n=20$ for each group, unaffected clams are not represented in graph most apparent at $20 \%$, and the stage of disease development was also more advanced at $20 \%$ than in the higher-salinity groups (Fig. 3).

\section{Immune parameters}

Total haemocyte counts and haemocyte viability

In control clams maintained at $20 \%$, the total haemocyte count (THC) was significantly lower than at other salinities both at T0 and T28 (Fig. 4a shows data for T28). However, the difference between counts at T0 and T28 was not statistically significant, indicating firstly that the low THC observed at $20 \%$ was a reproducible effect, and secondly that maintenance of the clams in the laboratory for up to $6 \mathrm{wk}$ did not significantly alter their THC. For T28 data, differences between salinity groups were observed when counts from SSW (control) and Vibrio tapetis-inoculated groups were combined into 1 data set for each salinity; i.e. the inoculation factor was disregarded. The THC increased with salinity, with a statistically significant difference between counts from 20 and $40 \%$ clams. When salinity was disregarded as a factor and counts from all SSW-inoculated clams were compared with those from all $V$. tapetis-inoculated clams, there was no statistically significant effect caused by inoculation. Examination of the differences between the clam groups revealed that inoculation with $V$. tapetis did depress the THC at all salinities. The difference was not significant at any salinity, and the effect of inoculation was only seen when compounded with the added stress of environmental salinity.

The percentage of dead cells in each sample did not significantly differ between groups.

\section{Cell-population dynamics}

Salinity alone caused a significant difference between granulocyte populations in haemolymph samples from the different clam groups, with the percentage of granulocytes decreasing with increasing salinity. When salinity data was pooled to determine any overall effect of inoculation, no significant difference was detected between control and inoculated clams. However, when the effects of salinity and inoculation were considered together (Fig. 4b), the percentage of granulocytes in the population decreased in response to inoculation at 30 and $40 \%$ salinity.

Salinity also affected the percentage of the hyalinocyte sub-population of cells, irrespective of their inoculation status, but inoculation did not have such a universal effect. Related inversely to the per- 

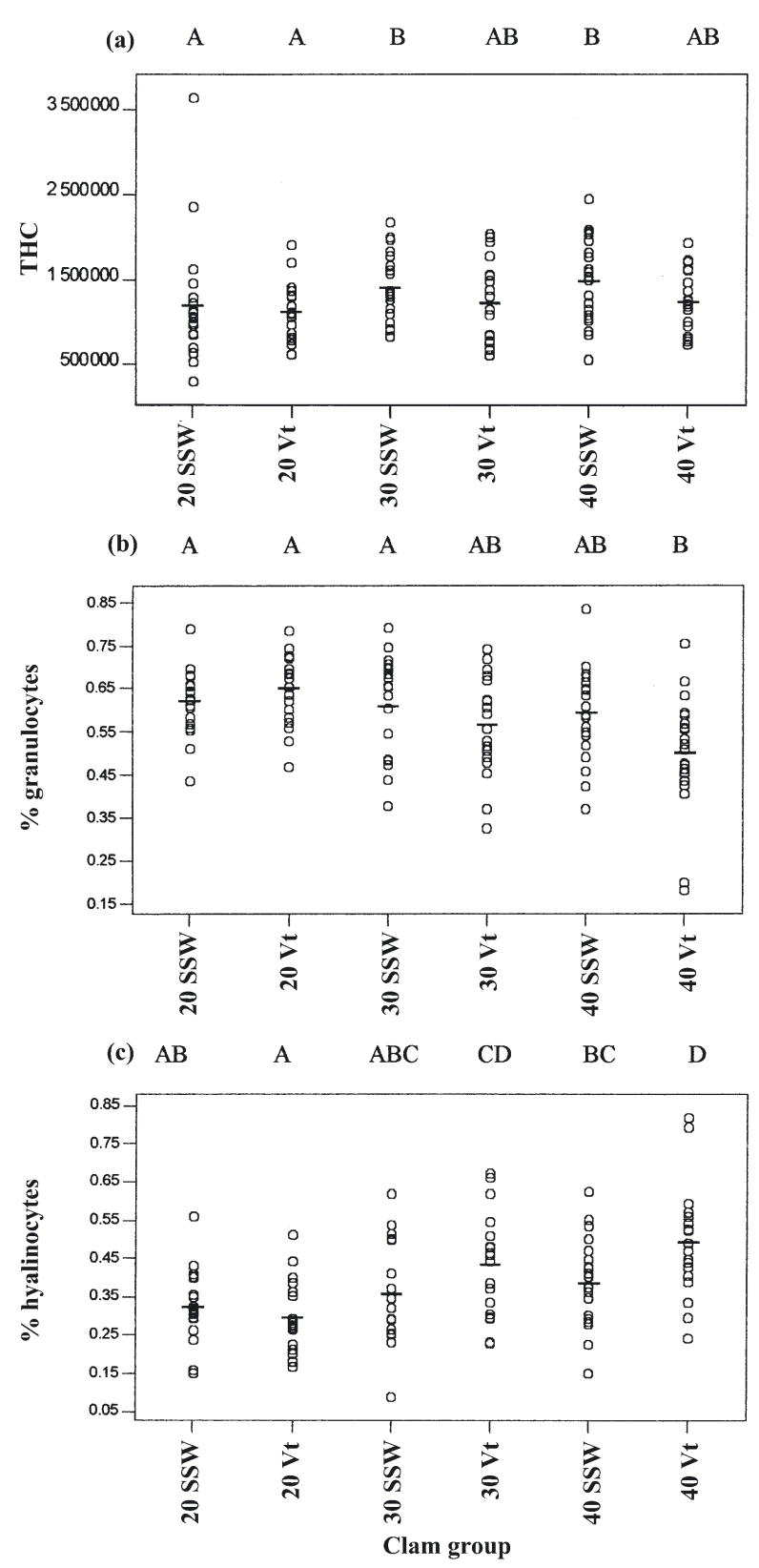

Fig. 4. Vibrio tapetis. Haemocyte population. (a) Total haemocyte count (THC) plotted for each clam group, with groups described by 2 factors, salinity $(20,30$ or $40 \%$ ) and inoculation (sterile seawater [SSW] or V. tapetis [Vt]); groups with matching letter codes at top of graph are not significantly different from each other, whereas those with different letters are ( $\mathrm{p}<0.05)$. (b) Percentage granulocytes in haemolymph. (c) Percentage hyalinocytes in haemolypmh

centage of granulocytes present in the haemolymph samples, the highest percentage of hyalinocytes was found at the highest salinity, as for THC (Fig. 4c). When the effects of salinity and inoculation factors are considered together, hyalinocytes increased in response to inoculation with Vibrio tapetis at 30 and $40 \%$, which again is a reflection (inverse) of the percentage of granulocytes in these samples.

\section{Lysozyme and protein concentration}

When the factors influencing lysozyme concentration were analysed separately, salinity alone caused significant differences in concentrations between groups, with the lowest amounts being produced at $30 \%$ and the highest at $40 \%$. Inoculation alone, without the contributing factor of salinity, had no effect. When the groups were analysed separately, inoculation had a significant effect at $40 \%$ only (Fig. 5).

The total protein concentration in the above samples was not significantly different between groups.

\section{Enzyme concentrations in cell and supernatant fractions of haemolymph}

In invertebrates, phenoloxidase leads to deposition of melanin as a host defence-reaction, and the activity of this enzyme was measured by its action on L-DOPA. Salinity had a significant effect on phenoloxidase activity in cells, with the highest concentration produced at $40 \%$ and the lowest at $20 \%$. Inoculation alone did not affect the levels of enzyme activity observed. When the effects of both factors were combined, inoculation with Vibrio tapetis slightly raised the phenoloxidase activity at each salinity, but the difference in levels measured was not significant (Fig. 6a). In the supernatant fractions of haemolymph, salinity and inoculation both had a significant effect on phenoloxidase activity, with significantly higher levels

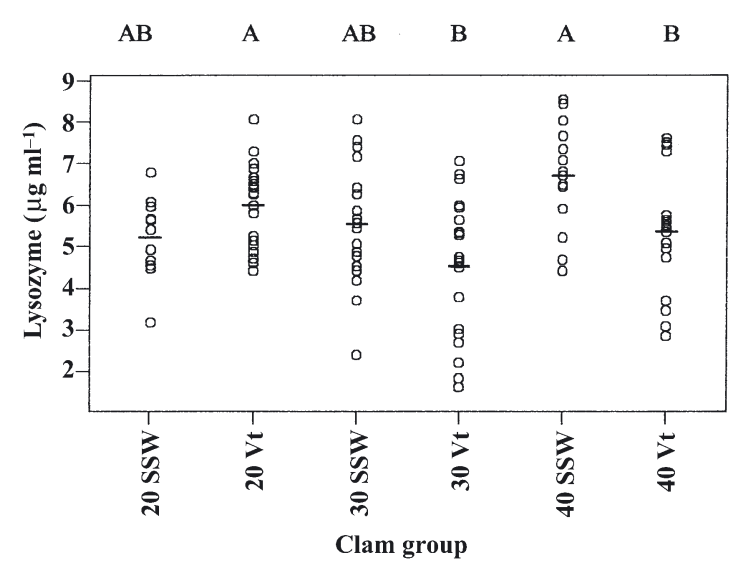

Fig. 5. Vibrio tapetis. Lysozyme levels in haemolymph. Further details as in Fig. 4 


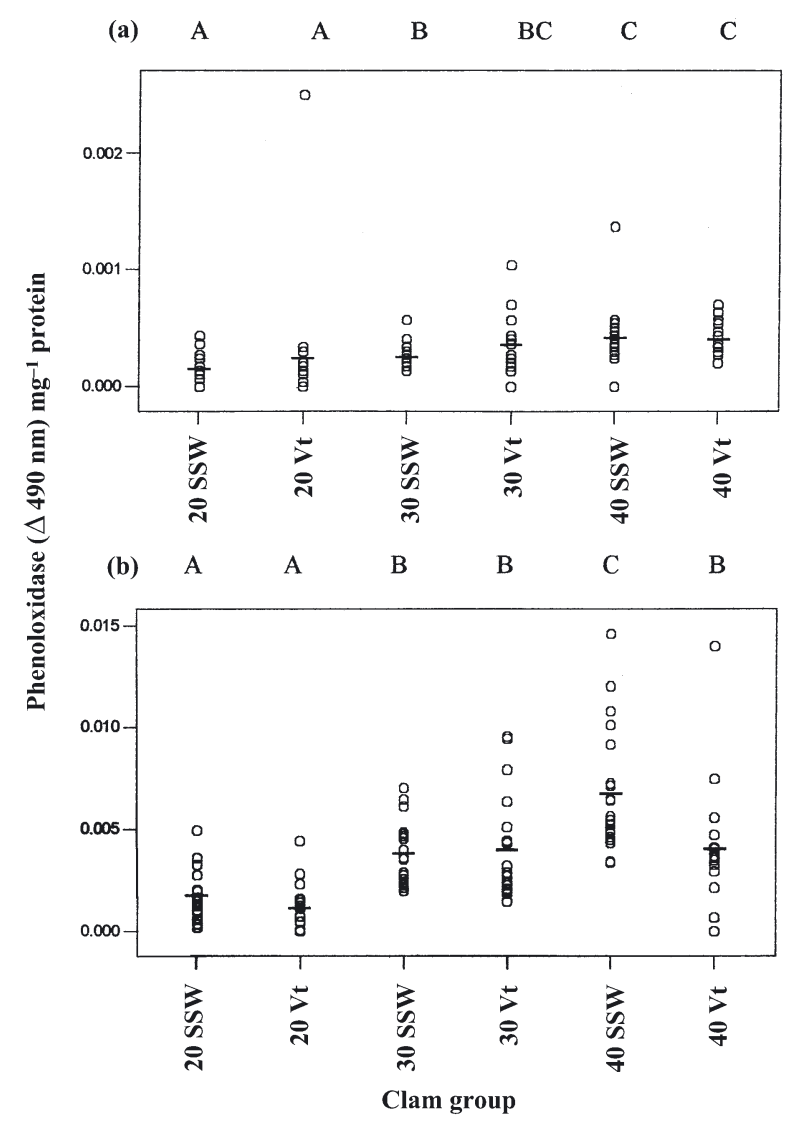

Fig. 6. Vibrio tapetis. Phenoloxidase levels in (a) haemolymph cell fractions and (b) haemolymph supernatant fractions. Further details as in Fig. 4

at $40 \%$ than at 20 or $30 \%$, and lower levels in clams inoculated with $V$. tapetis than in controls. The effect of these factors is clearly visible in Fig. $6 \mathrm{~b}$.

\section{Leucine aminopeptidase}

When the salinity and inoculation factors were considered separately, both had a significant effect on leucine aminopeptidase (LAP) concentrations in the cell fraction of clam haemolymph (Fig. 7a). For salinity, the highest LAP concentration was measured in clams held at $30 \%$. Clams inoculated with Vibrio tapetis had a lower enzyme concentration than SSW-inoculated controls. When the factors were considered together, inoculation with $V$. tapetis had a significant effect at all salinities.

As with LAP concentrations in cells, both salinity and inoculation had an effect on LAP concentrations in supernatant when these factors were considered separately, with the highest levels at 30\% and lower levels in Vibrio tapetis-inoculated clams than in SSW-inocu- lated controls (Fig. 7b). However, when the factors were considered together, no significant effect of inoculation was apparent at any salinity.

\section{Condition index}

The condition index of the clams was affected by salinity, with a significantly lower condition index in $40 \%$ clams compared to other groups when the inoculation factor was disregarded (Fig. 8). Inoculation did not alter the condition index, and there was no apparent interaction between inoculation and salinity that caused differences between groups.

\section{Haemocyte immunocompetence assays}

\section{Cytotoxicity assay}

In this assay, 3 factors contributed to the level of cellrounding displayed by haemocytes in response to in

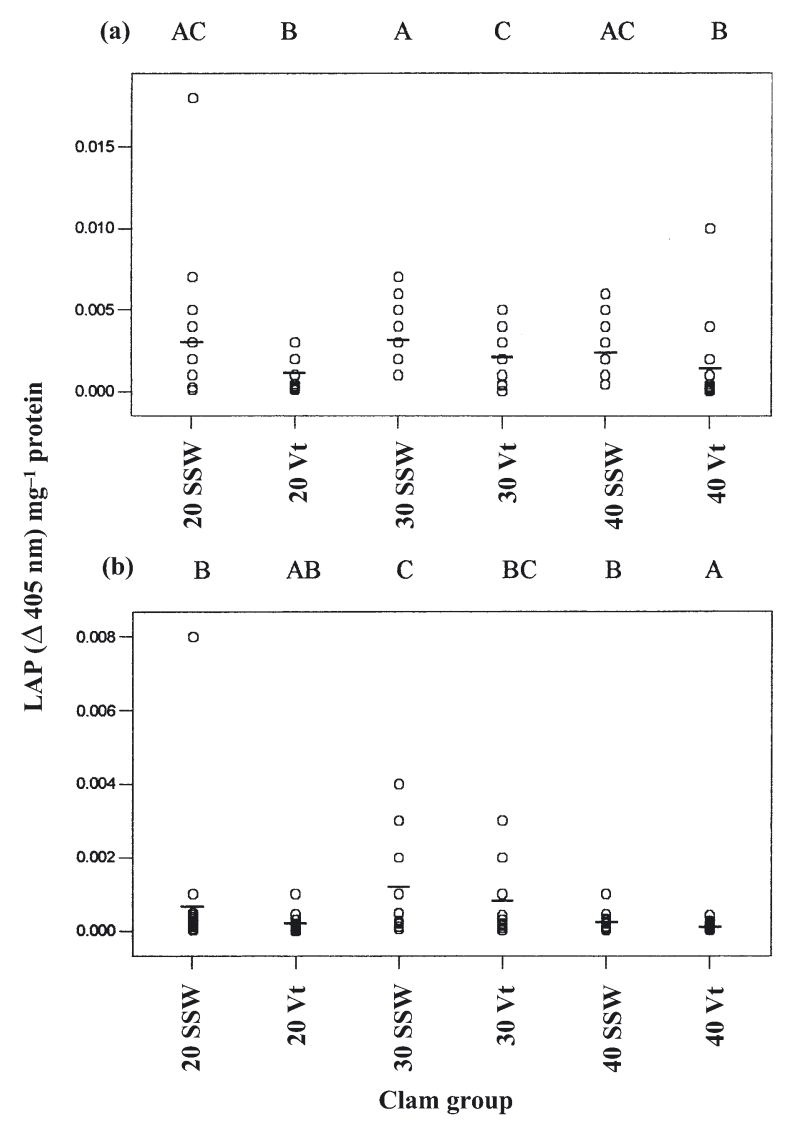

Fig. 7. Vibrio tapetis. Leucine amino-peptidase (LAP) levels, in (a) haemolymph cell fractions and (b) haemolymph supernatant fractions. Further details as in Fig. 4 


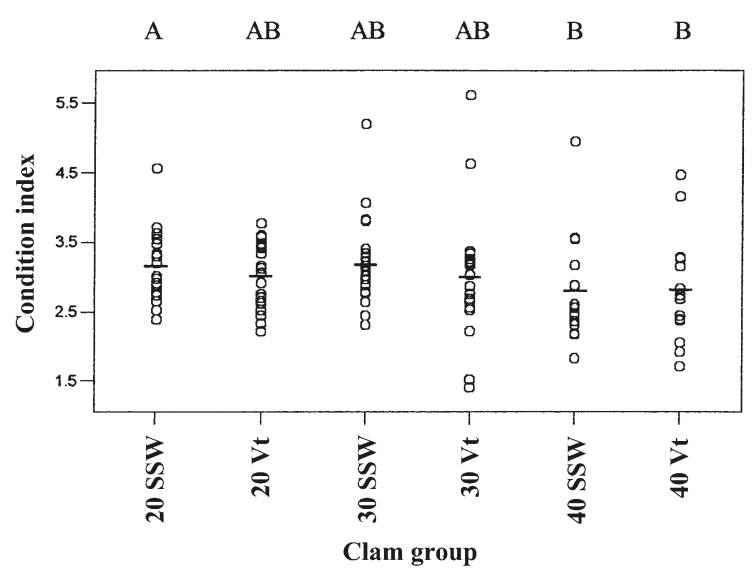

Fig. 8. Vibrio tapetis. Condition index of clams. Further details as in Fig. 4

vitro challenge with Vibro tapetis: the salinity at which the clams were maintained, clam inoculum (ASW or $V$. tapetis), and the salinity at which $V$. tapetis was cultured. Fig. 9a shows the response of each clam group to $V$. tapetis cultured at all 3 salinities pooled into 1 data group. Culture of the bacteria at different salinities did not noticeably alter the phenotype of the organism as determined by this assay as there was no significant difference in the cell-rounding response of any haemolymph pool to $V$. tapetis grown at the range of salinities.

Neither inoculation nor salinity of the clams affected the cell-rounding response, whether these factors were regarded separately or as interactive.

\section{Phagocytic index}

Salinity alone had a significant effect on phagocytic activity, but inoculation had no effect. The phagocytic index decreased with increasing salinity, indicating that at the highest salinity the cells were less capable of phagocytosis (Fig. 9b).

\section{Correlation between the above factors}

The correlations between the different parameters measured are summarised in Table 1. The total haemocyte count of the haemolymph samples appears to predict the responses of most of the other parameters, i.e. of 9 other parameters measured, the THC predicted the response of 8 . Only the percentage dead cells in the haemolymph samples was not correlated with the THC. The population dynamics of the haemolymph (i.e. percentage granulocytes and hyalinocytes pre-
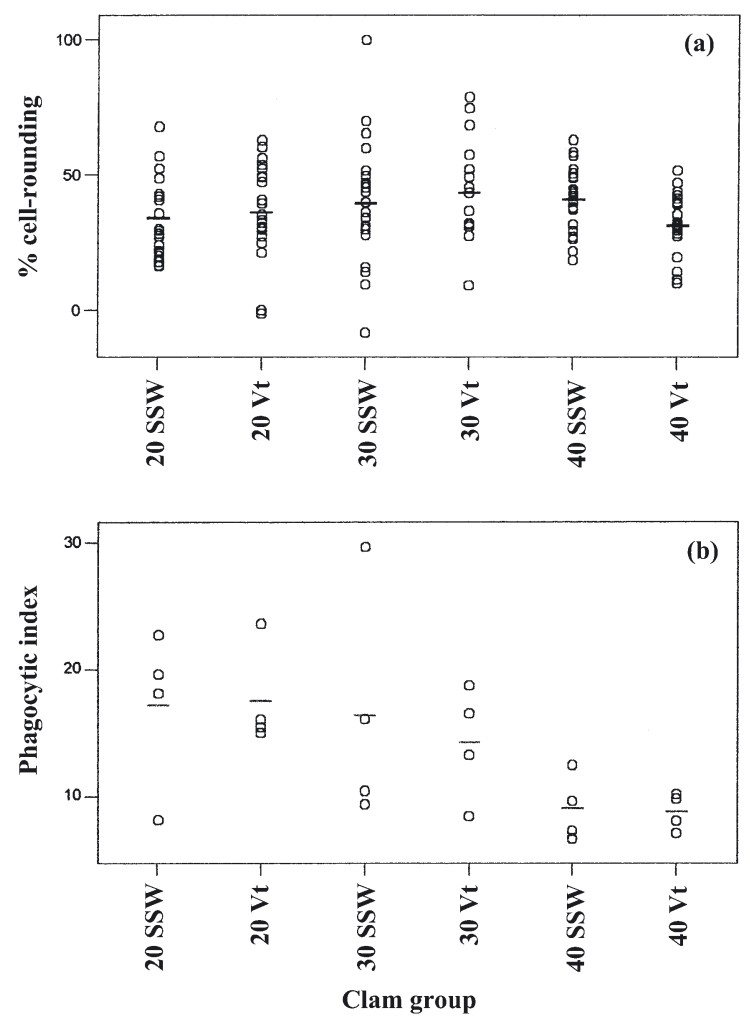

Fig. 9. Vibrio tapetis. Haemocyte immunocompetence. (a) Percentage haemocytes rounding in response to challenge with $V$. tapetis in in vitro assay. (b) Phagocytic index of haemocytes in an in vitro assay

sent) was also correlated with many of the other parameters, which further suggests the importance of the cellular fraction of haemolymph in predicting the immune status of clams.

\section{DISCUSSION}

Environmental salinity has previously been correlated with disease incidence in several bivalve species. Results from both field and laboratory studies have demonstrated a significant positive correlation between salinity and infection of the eastern oyster Crassostrea virginica by the parasite Perkinsus marinus (Crosby \& Roberts 1990, Gauthier et al. 1990, Paynter \& Burreson 1991, Chu et al. 1993). Similarly, the intensity of Haplosporidium nelsoni (MSX) disease of C. virginica was also found to increase with increasing salinity (Ford \& Haskin 1988). The present study is the first to relate environmental salinity to incidence of BRD in the Manila clam Ruditapes philippinarum by experimentally infecting clams maintained under controlled environmental conditions in the laboratory. 
Table 1. Vibrio tapetis. Correlation analysis between immune parameters measured in individual clams. $\mathrm{n}=110$ to 120 for each variable measured. Significant correlations $(p<0.05)$ in bold-face. THC: total haemocyte count; \% dead: percentage dead cells in haemolymph; CI: condition index; \% hyalin, \% gran: hyalinocyte and granulocyte counts respectively; Lyso: lysozyme DOPA and LAP cells/supern: levels in cell and supernatant fractions of haemolymph respectively; Asinv: arcsine square root

\begin{tabular}{|lcccccccc|}
\hline p-value & $\begin{array}{c}\text { THC } \\
(\log )\end{array}$ & \% dead & $\begin{array}{c}\text { CI } \\
(\log )\end{array}$ & $\begin{array}{c}\text { \% hyalin } \\
(\log )\end{array}$ & $\begin{array}{c}\text { \% gran } \\
\text { (Asinv) }\end{array}$ & $\begin{array}{c}\text { Lyso } \\
(\log )\end{array}$ & $\begin{array}{c}\text { DOPA } \\
\text { cells (log) }\end{array}$ & $\begin{array}{c}\text { LAP cells } \\
\text { supern (log) }\end{array}$ \\
\hline \% dead & 0.346 & & & & & & & \\
Ci (log) & $\mathbf{0 . 0 2 7}$ & 0.994 & & & & & \\
\% hyalin (log) & $\mathbf{0 . 0 0 2}$ & $\mathbf{0 . 0 0 2}$ & 0.074 & & & & \\
\% granul (Asinv) & $\mathbf{0 . 0 0 0}$ & $\mathbf{0 . 0 0 2}$ & 0.104 & $\mathbf{0 . 0 0 0}$ & & & \\
Lyso & $\mathbf{0 . 0 0 0}$ & 0.551 & $\mathbf{0 . 0 1 7}$ & $\mathbf{0 . 0 0 9}$ & $\mathbf{0 . 0 0 0}$ & & & \\
DOPA cells (log) & $\mathbf{0 . 0 1 5}$ & 0.429 & 0.462 & 0.347 & 0.215 & 0.673 & & \\
DOPA supern (Asinv) & $\mathbf{0 . 0 0 3}$ & $\mathbf{0 . 0 0 0}$ & 0.661 & $\mathbf{0 . 0 0 2}$ & $\mathbf{0 . 0 0 2}$ & 0.071 & 0.056 & $\mathbf{0 . 0 0 0}$ \\
LAP cells (Asinv) & $\mathbf{0 . 0 0 0}$ & 0.241 & $\mathbf{0 . 0 4 7}$ & $\mathbf{0 . 0 0 6}$ & $\mathbf{0 . 0 0 1}$ & $\mathbf{0 . 0 1 8}$ & 0.858 & $\mathbf{0 . 0 0 0}$ \\
LAP supern (Asinv) & $\mathbf{0 . 0 0 0}$ & 0.241 & $\mathbf{0 . 0 4 7}$ & $\mathbf{0 . 0 0 6}$ & $\mathbf{0 . 0 0 1}$ & $\mathbf{0 . 0 1 8}$ & 0.858 & $\mathbf{0 . 0 0 0}$ \\
\hline
\end{tabular}

Salinity affected the incidence of BRD development in clams in that $4 \mathrm{wk}$ after inoculation of clams, disease prevalence and the rate of disease progression was most advanced in clams that had been held at the lowest salinity, $20 \%$ o (Figs. 2 \& 3). Disease prevalence and severity decreased with increasing salinity, such that at $40 \%$ occurrence was no higher than the background incidence of disease displayed by clams prior to inoculation. It was noteworthy that at the end of the experiment, control clams expressed a similar low level of disease to that found in clams prior to inoculation with Vibrio tapetis. However, even in the control clams, disease was more advanced at the lowest salinity, suggesting that the environment was driving the disease process in all groups studied. The relationship between disease and salinity is the opposite of that found with MSX and Perkinsus marinus infection of Crassostrea virginica, where disease prevalence increased with salinity in both cases. In the case of MSX infection, the lower disease rate at low salinity was attributed to the inability of the infective agent (Haplosporidium nelsoni) to tolerate low salinity, such that environmental conditions are responsible for clearing the agent from oysters (Ford \& Haskin 1988). As low salinity can remove MSX, so too have high salinities been noted for their ability to inhibit bivalve pathogens (Motes \& DePaola 1996, Hauton et al. 2000). Such a dynamic resulting from differential host and pathogen salinity tolerances is not seen in the Manila clam/ $V$. tapetis infection model studied here, as the pathogen appears to tolerate wider ranges of salinity than the clam. $V$. tapetis was able to grow at salinities from 15 to $60 \%$ (albeit at a limited rate above $45 \%$ ) (Fig. 1), a range that could not be tolerated by the clams, whose metabolic rate is deleteriously affected at salinities below 15\% (Kim et al. 2001). The eastern oyster thrives in quite a different range of salinities, being found at sites with salinities from 5 to $30 \%$.
It has been suggested previously that elevated numbers of haemocytes might enable oysters to better resist infection (Fisher \& Newell 1986). The results of this study support this hypothesis, with THC significantly increasing with salinity as disease prevalence decreased. Inoculation of the clams with Vibrio tapetis depressed the THC slightly, but this depression was not statistically significant at any salinity examined.

Haemocyte sub-population dynamics are also affected by salinity, with the percentage of hyalinocytes present increasing with increasing salinity and THC, and a concomitant decrease being seen in the relative prevalence of granulocytes. Interestingly, the ability of the haemocytes to phagocytose (measured as the phagocytic index in this study) decreased in parallel to the decrease in numbers of granulocytes as salinity increased. It seems paradoxical that at high salinity disease prevalence was at its lowest level. As haemocytes were not more resistant to the cytotoxic effect of $V$. tapetis at high salinity, this suggests that haemocyte phagocytosis may not be the principal defence of clams against this pathogen, and that extracellular defences may be more significant (Ford 1988, Chu et al. 1993).

Measurable lysozyme concentrations in different bivalve species vary widely, with oysters producing only one-tenth to one-hundredth of the concentration produced by other species, and with different levels being detected within different tissues of the same individuals, as measured by a standard lysoplate method (McHenery et al. 1979). Low levels of lysozyme in the total haemolymph of the Manila clams (equivalent to approx. $6 \mu \mathrm{g} \mathrm{ml^{-1 }}$ hen egg-white lysozyme) were detected by increasing the incubation time of a standard substrate-reduction assay. The lysozyme level in Manila clam haemolymph was highest at the highest salinity, when disease prevalence was lowest. Inoculation of the clams with Vibrio tapetis generally reduced the lysozyme concentration, as found by 
Allam et al. (2000a). These results are in agreement with the findings of Chu et al. (1993), who found salinity to have more impact on lysozyme levels than infection status of the oysters. However, in contrast to the present study, they found lysozyme levels to decrease as salinity increased from 3 to $20 \%$, the lowest salinity tested here. Most significantly, the studies agree in that lysozyme levels were highest when disease prevalence was lowest.

Protein levels of the total haemolymph in this study did not alter significantly as the salinity of the clam environment changed, and this is consistent with other bivalve salinity studies (Fisher \& Newell 1986, Chu et al. 1993).

The condition index (CI) of the clams was affected by salinity. In contrast with the accepted relationship of CI to host disease-susceptibility (Lucas \& Beninger 1985, Paynter \& Burreson 1991, Chu et al. 1993), the CI was at its highest level in this study when disease prevalence was also at its highest, at $20 \%$. Similar results were found by C. Paillard et al. (unpubl. data) when studying the effect of temperature on disease susceptibility of Manila clams. A high condition index at low temperature was correlated with a susceptibility to BRD. The CI was slightly, but not significantly, lower in infected individuals than in controls. It is possible that although the CI was lower at low disease incidence, it was not sufficiently low to allow the disease to develop, i.e. it had not dropped to a level that could be considered pathologic. The clams in this laboratory experiment were fed a constant algal ration at all salinities. It has been shown that the metabolic rate of bivalves (measured as 'scope for growth' in Chilean scallops) increases with increasing salinity (Navarro \& Gonzalez 1998), so it is conceivable that the clams in this study had an increased metabolism at high salinity. Failure to feed them accordingly higher rations may have led to the relative decrease in their CI. It was observed that clams held at the highest salinity produced less faeces, and this might indicate that they were being forced to utilise their feed ration more efficiently, and were less inclined to allow the feed to process to 'waste'.

Of the immune parameters of the Manila clams measured in this study, more were significantly affected by salinity than by inoculation of the clams with a pathogen. As such, it appears that the environment of the clams had more impact on their immune defense status than did the presence of Vibrio tapetis. A low-salinity environment $(20 \%)$ was significantly associated with higher disease prevalence. In the field, Manila clams exhibit the highest levels of BRD during winter mortalities, when low salinity and oxygen depletion are known to be major environmental factors that trigger stress (Paillard 1992).
Of 9 other immune parameters, the THC correlated with 8 , suggesting that THC may provide a simple indication of Manila clam health and susceptibility to BRD. However, the increased haemocyte population did not appear to have a direct role in reducing disease levels, as measured by the phagocytic index and cytotoxicity assay. Of more importance may be the modulation in levels of other effectors of the innate immune system, such as lysozyme and phenoloxidase. Other effectors, such as small anti-bacterial peptides, characterised in other marine animal invertebrates (Schnapp et al. 1996) but yet to be studied in the Manila clam, may also have a significant function in host resistance to disease.

Acknowledgements. This work was carried out with financial support from the Commission of the European Communities, Agriculture and Fisheries (FAIR) specific RTD programme, CT98-4129, 'Environmental Factors and Shellfish Diseases'.

\section{LITERATURE CITED}

Allam B, Paillard C, Auffret M (2000a) Alterations in hemolymph and extrapallial fluid parameters in the Manila clam, Ruditapes philippinarum, challenged with the pathogen Vibrio tapetis. J Invertebr Pathol 76:63-69

Allam B, Paillard C, Howard A, Le Pennec M (2000b) Isolation of the pathogen Vibrio tapetis and defense parameters in Manila clam Ruditapes philippinarum cultured in England. Dis Aquat Org 41:105-113

Allam B, Ashton-Alcox KA, Ford SE (2002) Flow cytometric measurement of hemocyte viability and phagocytic activity in the clam, Ruditapes philippinarum. J Shellfish Res 21:13-19

Borrego JJ, Castro D, Luque A, Paillard C, Maes P, Garcia MT, Ventosa A (1996) Vibrio tapetis sp. nov., the causative agent of the brown ring disease affecting cultured clams. Int J Syst Bacteriol 46:480-484

Bradford M (1976) A rapid and sensitive method for the quantitation of microgram quantities of protein utilizing the principle of protein-dye binding. Analyt Biochem 72: 248-254

Chu FLE, LaPeyre JF, Burreson CS (1993) Perkinsus marinus infection and potential defense-related activities in Eastern oysters, Crassostrea virginica-salinity effects. J Invertebr Pathol 62:226-232

Crosby MP, Roberts CF (1990) Seasonal infection intensity cycle of the parasite Perkinsus marinus (and an absence of Haplosporidium spp.) in oysters from a South Carolina salt marsh. Dis Aquat Org 9:149-155

FAO (Food and Agriculture Organization of the United Nations) (1999) Yearbook of fishery statistics. FAO, Rome

Fisher WS, Newell RIE (1986) Seasonal and environmental variation in protein and carbohydrate levels in the haemolymph from American oysters (Crassostrea virginica Gmelin). Comp Biochem Physiol A 85:365-372

Ford SE (1988) Host-parasite interactions in eastern oysters selected for resistance to Haplosporidium nelsoni (MSX) disease: survival mechanisms against a natural pathogen. Am Fish Soc Spec Publ 18:206-224 
Ford SE, Haskin HH (1988) Comparison of in vitro salinity tolerance of the oyster parasite Haplosporidium nelsoni (MSX) and hemocytes from the host, Crassostrea edulis. Comp Biochem Physiol A 90:183-187

Gauthier JD, Soniat TM, Rogers JS (1990) A parasitological survey of oysters along salinity gradients in coastal Louisiana. J World Aquacult Soc 21:105-115

Hauton C, Hawkins LE, Hutchinson S (2000) The effects of salinity on the interaction between a pathogen (Listonella anguillarum) and components of a host (Ostrea edulis) immune system. Comp Biochem Physiol B 127:203-212

Kim WS, Huh HT, Huh SH, Lee TW (2001) Effects of salinity on endogenous rhythm of the Manila clam, Ruditapes philippinarum (Bivalvia: Veneridae). Mar Biol 138: 157-162

Lane E, Birkbeck TH (2000) Species specificity of some bacterial pathogens of bivalve molluscs is correlated with their interaction with bivalve haemocytes. J Fish Dis 23: 275-279

LeBorgne Y (1996) International trade in bivalve molluscs and the situation in France and Europe. Rev Sci Tech Off Int Epizoot 15:491-498

Lucas A, Beninger PG (1985) The use of physiological condition indexes in marine bivalve aquaculture. Aquaculture 44:187-200

McHenery JG, Birkbeck TH, Allen JA (1979) The occurrence of lysozyme in marine bivalves. Comp Biochem Physiol B 63:25-28

Motes ML, DePaola A (1996) Off-shore suspension relaying to reduce levels of Vibrio vulnificus in oysters (Crassostrea

Editorial responsibility: Albert Sparks,

Seattle, Washington, USA virginica). Appl Environ Microbiol 62:3875-3877

Navarro JM, Gonzalez CM (1998) Physiological responses of the Chilean scallop Argopecten purpuratus to decreasing salinities. Aquaculture 167:315-327

Paillard C (1992) Etiologie et characterisation de la maladie de l'anneau brun chez la palourde d'élévage Ruditapes philippinarum. PhD thesis, URA CNRS 1513, Université de Bretagne Occidentale, Brest

Paillard C, Maes P (1994) The brown ring disease in the Manila clam Ruditapes philippinarum: establishment of a classification system. Dis Aquat Org 19:137-146

Paillard C, Percelay L, LePennec M, Lepicard D (1989) Pathogenic origin of the brown ring disease in Tapes philippinarum (Mollusca: Bivalvia). C R Acad Sci Sér III Sci Vie 309:235-241

Paillard C, Maes P, Oubella R (1994) Brown ring disease in clams. Annu Rev Fish Dis 4:219-240

Paynter KT, Burreson EM (1991) Effects of Perkinsus marinus infection in the eastern oyster, Crassostrea virginica. II. Disease development and impact on the growth rate at different salinities. J Shellfish Res 10:425-431

Reid HI, Duncan HL, Laidler LA, Hunter D, Birkbeck TH (2003) Isolation of Vibrio tapetis from cultivated Atlantic halibut (Hippoglossus hippoglossus L.). Aquaculture 221: $65-74$

Schnapp D, Kemp GD, Smith VJ (1996) Purification and characterisation of a proline-rich antibacterial peptide, with sequence similarity to bactenecin 7 , from the haemocytes of the shore crab, Carcinus maenas. Eur J Biochem 240: $532-539$

Submitted: September 20, 2002; Accepted: April 17, 2003 Proofs received from author(s): August 25, 2003 